\title{
HISTÓRIA DO CAFÉ AGROFLORESTAL: RELATOS DO CEJA BATURITE
}

\section{REWRITING THE HISTORY OF COFFE AGROFORESTRY: REPORTS OF CEJA BATURITE}

Sofia Regina Paiva Ribeiro* Maria do Socorro Moura Rufino**

\begin{abstract}
Resumo: $O$ presente trabalho tem como objetivo apresentar o relato de experiência do Projeto "LeiturAção" CEJA Donaninha Arruda, em Baturité - Ceará, em parceria com o Mestrado Acadêmico em Sociobiodiversidade e Tecnologias Sustentáveis (MASTS), vinculado à Universidade da Integração Internacional da Lusofonia Afro-Brasileira, com o intuito de realizar oficinas temáticas com o corpo discente da EJA, contemplando o contexto histórico da cultura cafeeira com foco na educação ambiental. A atividade de extensão abrange o recorte temporal que compreende os meses de outubro e novembro de 2015. O arcabouco teórico que balizou as informações se respalda no estudo de vários autores, dentre eles: Freire, Girão, Martins, Gadotti. As atividades pedagógicas tiveram como base o tripé pesquisa, estudo e produção textual. Conclui-se que a iniciativa levou o educando a refletir sobre a relevância da cafeicultura para a região, bem como a necessidade de preservar o meio ambiente e desenvolver a ética ambiental.
\end{abstract}

Palavras chave: CEJA Baturité; café agroflorestal; meio ambiente.

\begin{abstract}
This study aims at describing the project "LeiturAção" carried out by CEJA Donaninha Arruda, in Baturité, Ceará, in parternship with the Academic Master's Degree in Biodiversity and Sustainable Technologies of University of International Integration of AfroBrazilian Lusophony. It was designed to hold thematic workshops about the historical context of the coffee culture, focusing on environmental education, to the students of EJA. It was carried out from October to November of 2015. The concepts used as theoretical background to the analysis are from Freire, Saes, Martins, Gadotti, among others. The pedagogical activities were based on research, study and textual production. It is possible to concluded that the initiative led the learner to reflect on the relevance of coffee cultivation to the region as well as the need to preserve the environment and develop environmental ethics.
\end{abstract}

Keywords: CEJA Baturité; coffee agroforestry; environment. 


\section{Introdução}

O Ceará, no Nordeste brasileiro, apresenta uma realidade territorial rica em diversidades naturais, contando com uma fauna e flora exuberantes, que contemplam uma geografia singular, compreendida por litoral, serra e sertão. Nesse contexto, a formação do Maciço Residual de Baturité, conhecido como Serra de Baturité, no centro-norte do Ceará, emerge, revelando uma paisagem que contrasta com os quentes e secos sertões que circundam o semiárido nordestino (CAVALCANTE; GIRÃO, 2006).

É nesse espaço geográfico que a produção cafeeira, historicamente, ocupa um lugar de destaque no ecossistema local, causando impacto no desenvolvimento econômico, social e cultural. De acordo com o contexto histórico, há quase dois séculos a cafeicultura está inserida na região. As primeiras mudas da planta chegaram em 1822, vindas de Pernambuco, enquanto as primeiras sementes foram plantadas no Sítio Mungaípe, em Baturité (GIRÃO, 2000; CATÃO, 1937).

Convém salientar que a região serrana, em 1990, se tornou a primeira e mais extensa Área de Preservação Ambiental - APA do Estado do Ceará. Segundo os dados do Sistema Nacional de Unidades de Conservação (SNUC), a iniciativa tem como um dos objetivos "proteger a diversidade biológica, disciplinar o processo de ocupação e assegurar a sustentabilidade do uso dos recursos naturais" (BRASIL, 2000, p. 9).

No entanto, apesar da relevância histórica e ambiental da cultura cafeeira para a região, verificouse (através de visitas in loco) que há poucas ações no contexto educacional envolvendo a temática no Centro de Educação de Jovens e Adultos Donaninha Arruda, conhecido popularmente por CEJA Baturité, a única escola, nessa modalidade, que abrange toda a região do Maciço.

Inobstante estas constatações, o CEJA de Baturité, em parceria com a Universidade da Integração Internacional da Lusofonia Afro-Brasileira - UNILAB, através de ações extensivas do Curso de Mestrado Acadêmico em Sociobiodiversidade e Tecnologias Sustentáveis - MASTS/UNILAB, vem promovendo ações com o intuito de propiciar o resgate histórico-cultural que envolve o café agroflorestal, bem como trabalhar alguns conceitos de "ecopedagogia"1.

A princípio, realizou-se uma investigação através da aplicação de questionários com perguntas objetivas e subjetivas destinadas aos discentes do ensino médio. $\mathrm{O}$ rol de questões foi aplicado em setembro de 2015 e contemplou $30 \%$ dos alunos que estavam frequentando o CEJA durante o referido mês, perfazendo um total de 50 educandos (dados do Sistema Integrado de Gestão Escolar - $\mathrm{SIGE}^{2}$ /CEJA).

As inquirições foram divididas em duas etapas, sendo a primeira de caráter objetivo, e fazia referência ao conhecimento básico sobre meio ambiente e as práticas pedagógicas envolvendo a temática; a segunda, subjetiva, pedia um relato histórico sobre a região. Cumpre detalhar que o CEJA Baturité atende uma área composta por 13 municípios: Aracoiaba, Aratuba, Acarape, Baturité, Barreira Capistrano, Guaramiranga, Itapiúna, Mulungu, Pacoti, Palmácia, Redenção e Ocara.

Dado seu âmbito de atuação e sua modalidade de ensino, constata-se que a instituição em alusão conta com um público bastante heterogêneo. De acordo com a LDB (1996), a escola deve oferecer oportunidades educacionais apropriadas, consideradas as características do alunado, seus interesses, condições de vida e de trabalho.

Após a aplicação dos questionários e coleta dos dados, deu-se início às atividades que têm como tema "Da História do Café Agroflorestal, Relatos do CEJA Baturité". As ações foram fruto do conhecimento adquirido com o ensino e a pesquisa, desenvolvidos dentro da universidade e no grupo de pesquisa "Polifenóis, antioxidantes e fibra dietética na saúde (POLIFIBAN), vinculado ao Conselho Nacional de Desenvolvimento Científico e Tecnológico, liderado pela coautora desse trabalho.

Para Jenize (2004, p. 3),

\begin{abstract}
A nova visão de extensão universitária passa a se constituir parte integrante da dinâmica pedagógica curricular do processo de formação e produção do conhecimento, envolvendo professores e alunos de forma dialógica, promovendo a alteração da estrutura rígida dos cursos para uma flexibilidade curricular que possibilite a formação crítica.
\end{abstract}

$\mathrm{Na}$ prática, as atividades foram realizadas por professores de linguagens e códigos ${ }^{3}$, contando com a presença de uma mestranda da UNILAB, que assessorou as ações e contribuiu com as ações pedagógicas. A dinâmica extensionista teve como foco o Projeto "LeiturAção" EJA, que contempla o tripé pesquisa, leitura e produção textual. Com a temática "café", foram várias diretrizes, dentre elas: resgate histórico, proteção ambiental e sustentabilidade.

As intervenções contemplaram o recorte temporal que abrange os meses de outubro e novembro de 2015, tendo como público-alvo os alunos com matrícula ativa que frequentavam as aulas de linguagens e códigos. Dentre as práticas realizadas, optou-se por ressaltar a oficina temática "Reescrevendo a História", em que os alunos traçaram um cronograma dos primeiros cultivares de café aos dias atuais, ato imprescindível para entender a relevância da temática em foco.

O diálogo com as demais áreas do conhecimento (ciências humanas e ciências da natureza) ocorre de forma interdisciplinar, uma vez que a temática 
contempla, em sua essência, a educação ambiental, estando, assim, em consonância com a Lei no 9.795/99, que dispõe sobre a Educação Ambiental e Institui a Política Nacional de Educação Ambiental. A lei preconiza, em seu art. $5^{\circ}$, inciso I, como um dos objetivos fundamentais o desenvolvimento de uma compreensão integrada do meio ambiente em suas múltiplas e complexas relações, envolvendo aspectos ecológicos, psicológicos, legais, políticos, sociais, econômicos, científicos, culturais e éticos.

Assim, a intertextualidade ocorre em várias abordagens temáticas, dentre elas pode-se citar: o respeito às leis ambientais vigentes; a produção cafeeira sombreada em sistema agroflorestal livre de defensivos químicos; o consórcio com outras culturas agrícolas (bananicultura); características de cultivos em área de proteção ambiental; o turismo ecológico, etc.

No que tange as atividades realizadas, pode-se destacar: pesquisas temáticas e interativas no laboratório de informática; leitura de livros, revistas e jornais; debates; rodas de conversas; confecção de poemas e poesias; elaboração e apresentação de slides, produção textual e a prática do Storytelling ${ }^{4}$.

Nesse sentido, é válido salientar que a extensão universitária contribui para a difusão de conhecimentos, ao passo que incrementa práticas de ensino aos alunos do CEJA Baturité, explorando a temática meio ambiente numa perspectiva regional, com realce para a importância da cultura cafeeira.

\section{O CEJA Donaninha Arruda}

O Centro de Educação de Jovens e Adultos (CEJA) Donaninha Arruda é uma instituição escolar pertencente à Rede Oficial de Ensino do Estado do Ceará, sob a dependência administrativa da Secretaria da Educação, planejada para a escolarização de Jovens e Adultos. A referida instituição é única nesta modalidade no Maciço de Baturité e tem como clientela alunos de 13 localidades.

A Educação de Jovens e Adultos (EJA) é uma modalidade de ensino destinada a educandos que foram impossibilitados de continuar seus estudos, ou não tiveram acesso à educação formal na idade apropriada. Entre as peculiaridades da EJA, pode-se ressaltar: matrícula inicial para o ensino fundamental é realizada a partir de 15 anos e para o ensino médio acima de 18 anos, podendo ser efetuada em qualquer época do ano.

A EJA está amparada pela Lei 9394/96, Lei de Diretrizes e Bases da Educação Nacional (LDB). Sua definição está no artigo 37 do citado diploma, como sendo destinada àqueles que não tiveram acesso ou à continuidade de estudos no ensino fundamental e médio na idade própria. A Constituição Federal de 1988, no artigo 208, inciso I, garante o acesso e a permanência ao ensino fundamental a todos. As aulas são ministradas levando em consideração as peculiaridades e heterogeneidade presentes na sua clientela.

Além da matrícula convencional, existe a modalidade diagnóstico, na qual o aluno é submetido a uma avaliação de conhecimento, que consiste numa prova de conhecimentos básicos de português e matemática, com conteúdo da primeira etapa da educação básica $\left(1^{\circ}\right.$ ao $5^{\circ}$ ano), e não há obrigatoriedade de apresentar transferência ou documento comprobatório de conclusão do nível anterior (art. $5^{\circ}$ e 24, da LDB 9.394/96). Dessa forma, se o aluno atingir a média da escola, que consiste em $60 \%$ de acertos, ele automaticamente é promovido ao $6^{\circ}$ ano. De acordo o artigo 35 do Regimento Escolar CEJA 2015, "Os cursos do CEJA diferenciam-se fundamentalmente dos cursos da escola regular pelo seu regime, estrutura, metodologia, período de funcionamento e duração dos cursos".

Ao contrário da escola regular, o CEJA tem atendimento semipresencial, com frequência flexível. Assim, o aluno pode escolher horário, turno e tempo de permanência na escola, respeitando sua necessidade e disponibilidade. Entretanto, após dois meses de ausência, é necessário a reativação da matrícula.

Outra peculiaridade da instituição é a comunicação direta entre docente e discente, através do atendimento individualizado, constituindo-se na base pedagógica que fundamenta o processo de ensino e aprendizagem da EJA, favorecendo o intercâmbio de experiências e saberes empíricos. Para trabalhar com jovens e adultos, faz-se necessário uma pedagogia diferenciada, a andragogia 5 .

Paulo Freire (2000), figura emblemática no contexto educacional da EJA, afirmava que o ato educativo é inerente ao ser humano. Diante desse ensinamento, ressalta-se que sempre é tempo para buscar novos conhecimentos. Esse cenário é observado na escola paradigma. De acordo com os dados do Sistema Integrado de Gestão Educacional SIGE/CEJA (2017), o CEJA Baturité conta com uma média de 1.000 atendimentos mensais entre alunos do ensino fundamental e médio.

No que tange a grade curricular, o aluno pode escolher qual a sequência de matérias que ele deseja fazer, até concluir todas as etapas. Os atendimentos/aulas são realizados em salas temáticas por área do conhecimento: Linguagens e Códigos, Ciências Humanas e Ciências da Natureza, proporcionando a interação entre docentes e discentes.

Além das temáticas curriculares, a inserção de projetos é uma realidade presente no CEJA, onde os alunos são motivados a vivenciar os conteúdos através de uma análise interdisciplinar, dinâmica e contextualizada. Nessa perspectiva, o Projeto 
"LeiturAção" tanto fortalece o hábito da leitura e produção textual, como contribui para que os educandos se tornem mais conscientes, críticos, autônomos e comprometidos com o próximo e o meio ambiente.

Ressalta-se, ainda, que o projeto em questão, através da parceria com o MASTS, trouxe uma abordagem mais ampla sobre a temática ambiental, vista através do contexto da cafeicultura local que, por sua vez, se destaca por ser agroflorestal.

\section{Histórico: aspectos gerais do café na região do Maciço de Baturité}

O contexto histórico é representado pelas dinâmicas socioculturais, econômicas e políticas que envolvem os costumes de cada época. O café faz parte dessa história. $\mathrm{O}$ fruto é originário do continente africano, mais precisamente da Etiópia - um país localizado na região nordeste da África, onde faz parte da vegetação nativa (FERRAZ, 2013).

De acordo com Neves (1974), de lá foi levado para a Arábia. Os árabes foram os primeiros a criar um polo agrícola e comercial cafeeiro. Em sequência, o café foi difundido para o Egito (século XVI), depois para a Turquia. $\mathrm{O}$ produto ganhou destaque ao chegar à Europa (século XVII): na Itália e Inglaterra e, logo após, na França, Alemanha, Suíça, Dinamarca e Holanda.

Os holandeses disseminaram a cultura cafeeira pelo mundo e, com a ajuda dos franceses e portugueses, o café chegou às Américas, sendo os Estados Unidos, atualmente, o maior consumidor e importador mundial desse produto. Por se tratar de uma bebida estimulante e não alcoólica, sua difusão e consumo adequou-se a vários ambientes, ganhando adeptos pelo mundo e transformando-se em praxe de sociabilidade.

Quanto ao Brasil, relevante é o texto da Revista Cafeicultura (2011):

O café chegou ao norte do Brasil, mais precisamente em Belém, em 1727, trazido da Guiana Francesa para o Brasil pelo Sargento-Mor Francisco de Mello Palheta a pedido do governador do Maranhão e Grão-Pará, que o enviara às Guianas com essa missão. Já naquela época o café possuía grande valor comercial [...]

Devido às nossas condições climáticas, o cultivo de café se espalhou rapidamente, com produção voltada para o mercado doméstico.

Mello Palheta, natural de Belém do Pará, trouxe para o Brasil cinco mudas e mais de mil sementes da planta, configurando-se como um dos primeiros cafeicultores do país (GALETI, 2004). No Ceará, o café chegou no século XVIII, sendo as mudas trazidas do Jardim das Plantas de Paris por José Xerez Furna Uchoa. A primeira muda foi introduzida no sítio Úrsula, na serra de Meruoca (GIRÃO, 2000; STUDART, 1928).

No Maciço de Baturité, mais precisamente na região serrana, os primeiros registros de plantações de café datam de 1822 e 1824, em Baturité e Mulungu, respectivamente. As mudas do cafeeiro deram início a uma atividade lucrativa e bem-sucedida, que trouxe emprego e renda para a região, visto tornar-se, em meados do século XIX, a principal atividade econômica local ${ }^{6}$.

A princípio, as técnicas de cultivo na região eram realizadas a pleno sol, uma prática comum em todo o país. Escalante (1997) revela que, no Brasil, desde o início do século XIX, a lavoura do café caracterizou-se pelo monocultivo ao sol, com baixo nível de diversidade biológica. Registre-se que a retirada da mata nativa para o plantio do café promoveu modificações no solo, entre elas o conteúdo de matéria orgânica e a disponibilidade de nutrientes. Devido às condições sensíveis de relevo e do solo da região, não demorou muito para haver um alto nível de degradação e, consequentemente, a queda na produção. Segundo Dean (1997), os primeiros produtores de café aplicavam técnicas tradicionais de derrubada e queimada da mata, prática comum na produção de cana-de-açúcar e algodão.

Para Silva (2015), os agricultores perceberam que os pés de café que ficavam sob a copa de árvores resistiam melhor às intempéries, protegendo as plantas do excesso de radiação solar e da chuva. Diante de tal constatação, o café passou a ser cultivado sob a sombra do Pithecellobium polycephalum (camunzé) e da Inga fagifolia (ingazeira), dentre outras plantas nativas ${ }^{7}$.

Essa técnica de plantio está em consonância com o que prelecionam Santana e Bahia Filho (2003), quando mencionam que a boa qualidade do solo constitui-se como um elo entre as práticas agrícolas e a agricultura sustentável. Nesse sentido, Fernandes, Silva e Pereira (2011) verificaram que o sombreamento favoreceu a conservação dos nutrientes naturais do solo, a produção de húmus e a redução de pragas invasoras, o que ocasionou a recuperação da atividade cafeeira na área serrana.

Atualmente, na forma sombreada, a lavoura cafeeira local está protegida da incidência intensa do sol, as folhas caídas das árvores fertilizam o solo, adubando naturalmente a terra. Com o consórcio, houve o controle natural das epidemias e crescimento da produtividade. O café sustentável começou a ser intercalado com outras culturas, proporcionando um sistema diversificado composto por árvores de sombra, fruteiras e agricultura de subsistência. 


\section{O Sistema Agroflorestal e o consórcio de culturas agrícolas}

O café é um alimento de grande aceitação, pois é um produto natural, com sabor e aroma característicos, que pode ser tomado em diversos locais e ocasiões. Dentre os vários benefícios da bebida, é também conhecida como fonte de antioxidantes para o organismo humano. Segundo a Associação Brasileira da Indústria de Café - ABIC (2016):

\begin{abstract}
O consumo de café como importante fonte de antioxidante da dieta, pode inibir as inflamações e, portanto, reduzir o risco de doenças cardiovasculares e outras doenças inflamatórias prolongadas. As inflamações têm muito a ver com o estresse oxidativo, e qualquer processo que reduza estas inflamações beneficiam consideravelmente nossa saúde e bemestar.
\end{abstract}

Além desse atributo, evidencie-se o fato de o café sombreado em sistema agroflorestal da região serrana de Baturité ser cultivado livre de agrotóxicos e adubos químicos, unindo qualidade e sustentabilidade. A lavoura local respeita as leis ambientais vigentes $\mathrm{e}$ as etapas de colheita, secagem, torrefação, beneficiamento e embalagem, que são feitas de forma artesanal, o que, sem dúvida, agrega valor ao produto. "A cafeicultura no Maciço de Baturité é uma das poucas no Brasil em sistema agroflorestal tradicional e orgânico" (EMBRAPA, 2011).

Para Bernardes e Khatounian (2013), "Embora seja possível fazer produção orgânica de café a pleno sol, o conjunto de efeitos positivos da arborização facilita sobremaneira o manejo orgânico, pois diminui a necessidade de insumos externos e o risco da atividade". Com menos gastos para manter a cultura, o produto se torna mais viável economicamente. Nas palavras de Beer (1997), as lavouras arborizadas, ou em consórcios agroflorestais, possibilitaram ao produtor um maior retorno econômico, especialmente para o pequeno produtor.

Convém salientar que tanto o manejo agroflorestal quanto o orgânico, tendências ecológicas na agricultura, constituem tecnologias relevantes para a recuperação dos solos (ALFARO-VILLATORO et al., 2004). Os sistemas agroflorestais são considerados opções agroecológicas do uso da terra e apresentam várias vantagens, no que tange os principais componentes da sustentabilidade, ou seja, o econômico, o social e o ambiental (DANIEL et al., 1999).

O café é mais que um produto voltado para o agronegócio, sua relevância está interlaçada ao contexto histórico, social, econômico e ambiental da região. Considerando essa amplitude de significados, é fundamental que a cultura desse produto seja abordada no contexto dentro da sala de aula.

\section{O Projeto "LeiturAção" e a temática ambiental}

É cediço que a escola é um locus singular para formação do caráter e a construção de princípios morais e éticos. Nesse âmbito, o educando deve ser direcionado a utilizar os conhecimentos aprendidos de forma coerente e eficaz. Para que isso aconteça, urge que o conhecimento adquirido vá além dos conteúdos curriculares, prezando por uma formação que prepara o indivíduo para o mundo do trabalho.

Nessa perspectiva, o Projeto "LeiturAção" EJA, desenvolvido pelo CEJA, tem caráter interdisciplinar e visa abordar temáticas que levam à formação autônoma, crítica e reflexiva do indivíduo, objetivando uma aprendizagem que vá além dos conteúdos curriculares, como forma de valorizar tanto o conhecimento empírico como os valores humanos. Para tanto, a metodologia utilizada nessa modalidade é a andragogia, que busca orientar/ensinar o adulto através da autogestão, prezando pelo respeito à idade e à maturidade intelectual de cada indivíduo (GIL, 2011).

É nesse contexto, direcionado para a formação integral do educando, que o projeto desenvolve ações que buscam ampliar a percepção crítica do educando e desenvolver a competência da leitura e da escrita. De acordo com a LDB $n^{\circ}$ 9394/96, art. 32, para uma educação de qualidade, faz-se necessário "O desenvolvimento da capacidade de aprender tendo como meio básico o pleno desenvolvimento da leitura, da escrita e do cálculo".

Para Martins (2013, p. 146), "o aluno é um agente de sua aprendizagem, interagindo e se apropriando de saberes que contribuem para sua autonomia". Dentre os objetivos do projeto, pode-se citar: desenvolver a criticidade; fortalecer a capacidade de fazer escolhas individuais e coletivas. Nesse diapasão, a relação da universidade com a comunidade escolar, através da extensão universitária, é relevante para desenvolver ações "socioeducativas" que priorizam a superação das condições de desigualdade e exclusão social (SILVA, 2011).

Assim, as ações desenvolvidas pelos professores do CEJA e uma estudante mestranda do MASTS/UNILAB envolvem uma releitura na história do Maciço de Baturité, levando em consideração os aspectos históricos, sociais e ambientais.

Como a educação ambiental tem caráter multidimensional, a discussão sobre o tema possibilita divagar sobre o campo da interdisciplinaridade. A ética ambiental e o comportamento sustentável são atitudes que devem fazer parte do nosso dia a dia e precisam estar em evidência, haja vista ser uma discussão de cunho global. Daí a relevância de uma formação que leve o educando à reflexão, indo além das habilidades básicas de "codificação" e "decodificação" da palavra. Para Koch (2011, p.17), "os sentidos do texto são construídos na interação texto - sujeitos". 
Dessa forma, optou-se por conhecer os impactos socioambientais através do estudo da cafeicultura da região serrana de Baturité. Preliminarmente, o estudo do contexto histórico é essencial para entender que a lavoura cafeeira, a princípio, trouxe impactos negativos para o meio ambiente. Entretanto, hodiernamente, é um exemplo de agricultura sustentável. Como afirma Saes (2006), a produção de cafés sustentáveis na região de Baturité, no Estado do Ceará, é um exemplo de respeito ao meio ambiente e à sociedade.

De acordo com as Diretrizes Curriculares Nacionais para a Educação Ambiental, no seu art. $2^{\circ}$, "A Educação Ambiental é uma dimensão da educação, é atividade intencional da prática social, que deve imprimir ao desenvolvimento individual um caráter social em sua relação com a natureza e com os outros seres humanos [...]”. (BRASIL, 2012, p. 2).

Em consonância com a Conferência Intergovernamental de Tbilisi (1977), a formação de alunos com foco no compromisso com o meio ambiente é relevante, desenvolve habilidades e modifica suas atitudes em relação à manutenção do equilíbrio da natureza. Dessa forma, a educação ambiental é um processo de reconhecimento de valores e está relacionada com a prática das tomadas de decisões éticas que conduzem para a melhoria da qualidade de vida.

Para compreender o nível de conhecimento acerca da temática junto aos alunos do CEJA Baturité, optou-se por fazer uma pesquisa através da aplicação de questionários com perguntas objetivas e subjetivas. A primeira etapa envolveu a temática meio ambiente $\mathrm{e}$ a segunda retratou o conhecimento do discente sobre o contexto histórico regional.

Dentre as inquirições, duas chamaram a atenção pelas respostas obtidas. Constatou-se que a temática meio ambiente é constantemente abordada pelos professores em sala, 42\% (Tabela 1). Entretanto, quando o foco é descrever um contexto histórico referente ao Maciço de Baturité, a grande maioria (72\%) deixou de responder. Dos que responderam, apenas $12 \%$ fizeram referência à cafeicultura, relatando que a região já foi uma referência na produção de café no estado do Ceará.

Outra parcela dos alunos citou a linha férrea que cruza a região, porém desconheciam a correlação desta obra com história da produção do café. Como se sabe, fora construída a partir de 1873 para possibilitar o escoamento dos grãos para o porto em Fortaleza. Segundo Ferreira (1989), a via férrea de Baturité tornase realidade graças ao cultivo do café.
Tabela 1 - Frequência de abordagem da temática meio ambiente em sala de aula.

\begin{tabular}{|l|c|c|}
\hline \multicolumn{1}{|c|}{ Opções } & Respostas & $\%$ \\
\hline Constantemente & 21 & $42 \%$ \\
\hline Esporadicamente & 29 & $58 \%$ \\
\hline Nunca & 00 & $00 \%$ \\
\hline Total & 50 & $100 \%$ \\
\hline
\end{tabular}

Fonte: Pesquisa realizada no CEJA Donaninha Arruda (set/2015)

Os questionários foram aplicados em setembro de 2015, com alunos que cursavam o ensino médio. Os dados tiveram como base $30 \%$ dos discentes que frequentavam a EJA no referido mês, totalizando 50 inquiridos. $\mathrm{O}$ quantitativo de alunos teve como base o Sistema Integrado de Gestão Escolar - SIGE/CEJA (2015). Logo após a catalogação dos dados, foram planejadas as intervenções a serem utilizadas nos meses subsequentes, outubro e novembro/2015. Dentre as atividades realizadas no Projeto "LeiturAção", pode-se ressaltar (Tabela 2):

Tabela 2 - Ações pedagógicas realizadas pelos professores do CEJA e extensão universitária - MASTS/UNILAB.

\begin{tabular}{|l|l|}
\hline \multicolumn{1}{|c|}{ Área do conhecimento } & \multicolumn{1}{c|}{ Interdisciplinaridade } \\
\hline Linguagens e Códigos & A prática do Storytelling. \\
\cline { 2 - 2 } & Pesquisas interativas no laboratório de informática. \\
\cline { 2 - 2 } Ciências da Natureza & Oficinas de produção textual. \\
\cline { 2 - 2 } & Divulgar os principios da "ecopedagogia". \\
\cline { 2 - 2 } & $\begin{array}{l}\text { Conhecer as vantagens do alimento orgânico. } \\
\text { Traçar educação ambiental através do contexto da } \\
\text { cafeicultura. }\end{array}$ \\
\hline Ciências Humanas & A História do Café das origens aos dias atuais. \\
\cline { 2 - 2 } & A sustentabilidade e a APA de Baturité. \\
\cline { 2 - 2 } & $\begin{array}{l}\text { Debates sobre preservação ambiental no contexto } \\
\text { atual - na região do Maciço. }\end{array}$ \\
\hline Fonte: Autora (set/2015) &
\end{tabular}

Nesse contexto, o projeto da área de linguagens e códigos da EJA e as ações extensionistas MASTS/UNILAB propiciaram aos alunos do CEJA acrescentar conhecimentos acerca da história do Maciço de Baturité através da cafeicultura e, consequentemente, ampliar a compreensão sobre o meio ambiente num contexto geral e regional.

\section{Considerações Finais}

O educando deve entender que faz parte de um todo, sendo coparticipante de uma história que, a cada dia, é construída e reconstruída. A sensação de pertencimento e o respeito consigo e com o próximo fazem do educando um sujeito crítico comprometido e engajado. Com esse norte, o Projeto "LeiturAção", realizado no Ceja Baturité, teve o propósito de trabalhar a leitura e produção textual de forma dinâmica, contextualizada e interdisciplinar, em que os temas abordados $\mathrm{e}$ as oficinas realizadas pelos professores de linguagens e códigos, com a 
contribuição das demais áreas do conhecimento, intentaram levar o docente a reconhecer-se como um sujeito histórico, cujos atos e ações possam refletir tanto na geração atual como nas futuras.

Nas oficinas teórico-práticas, os aspectos metodológicos foram concretizados levando em consideração a andragogia, a prática do Storytelling e a educação ambiental através do foco da ecopedagogia.

Constatou-se, através da pesquisa, que a temática meio ambiente é vislumbrada no contexto geral, entretanto, não é dada a devida relevância à temática regional. Ante essa realidade, a opção por trabalhar de forma extensiva o Projeto "LeiturAção" deu-se tanto pelo seu caráter interdisciplinar quanto pela versatilidade das oficinas de leitura e escrita, que estimularam o aluno a envolver-se mais nas ações escolares e, consequentemente, tornaram-se sujeitos mais cientes e participantes do meio em que vivem.

Como se infere, no relato de experiência ora apresentado, a participação extensiva da universidade na escola teve um papel singular, pois a UNILAB trouxe, através do mestrado voltado para a sociobiodiversidade e tecnologias sustentáveis, uma releitura de ações direcionadas ao contexto histórico social, à conservação ambiental e ao crescimento econômico da região do Maciço de Baturité.

Por fim, o discente é motivado a participar do sarau poético intitulado "Café com Letras", realizado há mais de uma década no CEJA de Baturité. O conteúdo do evento decorre das produções literárias, em forma de conto ou poesia, ocorridas no decorrer do período letivo e guardadas/catalogadas na sala de multimeios para, ao final do ano, na ocasião do sarau, serem divididas em categorias: exposição de painéis, livretos e apresentação oral.

\section{Referências}

ALFARO-VILLATORO, M. A. et al. Produção de café em sistema agroflorestal. Seropédica: Embrapa Agrobiologia, 2004. 36p.

\section{ASSOCIAÇÃO BRASILEIRA DA INDÚSTRIA DE CAFÉ - ABIC, 2016. Disponível em: \\ http://www.abic.com.br/publique/ cgi $/$ cgilua.exe/sys/start.htm?infoid $=161 \&$ sid $=81$. Acesso em: 10 mai. 2017.}

BEER, J. Café bajo sombra en América Central: hace falta más investigación sobre este sistema falta más investigación sobre este sistema agroflorestal exitoso? Agroforestería en las Américas, Cali, v. 4, p. 4-5, 1997.

BRASIL, Ministério do Meio Ambiente. Sistema Nacional de Unidades Conservação - SNUC., 2000. Disponível em: http://www.mma.gov.br/areas-protegidas/sistema-nacionalde-ucs-snuc. Acesso em: 18 mai. 2017.
. Ministério da Educação. Lei de Diretrizes e Bases da Educação Nacional. Lei ${ }^{\circ}$ 9.394, de 20 de dezembro de 1996. Disponível em:

http://www.planalto.gov.br/ccivil_03/leis/_L9394.htm.

Acesso em: 15 mai. 2017.

. Ministério da Educação. Diretrizes Curriculares Nacionais para a Educação Ambiental. Resolução $\mathrm{CNE} / \mathrm{CP} \mathrm{n}^{\circ} 2$, de 15 de junho de 2012. Disponível em: $\mathrm{http}: / /$ conferenciainfanto.mec.gov.br/images/ pdf/diretrizes.pdf. Acesso em: 14 mai. 2017.

Ministério da Agricultura, Pecuária e Abastecimento. Empresa Brasileira de Pesquisa e Agropecuária - EMBRAPA. Café agroflorestal é tema de simposio no Maciço de Baturité - Ceará. Disponível em: http://www.ceinfo.cnpat.embrapa.br/noticia_materia.php?id $=1247$. Acesso em: 14 mai. 2017 .

BERNARDES, M. S.; KHATOUNIAN, C. A. Cafeicultura a pleno sol supera o vantajoso sistema agroflorestal. Revista Visão Agrícola, n.12, jan. 2013.

CATÃO, P. Baturité - Subsídio geográfico, histórico e estatístico. Revista do Instituto do Ceará, Fortaleza, t. 51, 1937.

CAVALCANTE, A. de M. B.; GIRÃO, J. História da Área de Proteção Ambiental da Serra de Baturité. In: PINHEIRO, Daniel R. de C. (Org.). Desenvolvimento Sustentável: desafios e discussões. Fortaleza: ABC Editora, 2006, p. $367-$ 384 .

DANIEL, O.; COUTO, L.; GARCIA, R.; PASSOS, C. A. M. Proposta para padronização da terminologią empregada em sistemas agroflorestais no Brasil. Revista Árvore, Viçosa, v.23, n.3, p.367-370, 1999.

DEAN, W. A Ferro e Fogo: a história da devastação da Mata Atlântica brasileira. São Paulo: Companhia das Letras, 1997. 484p.

\section{DECLARAÇÃO DE TBILISI. Conferência}

Intergovernamental de Tbilisi. Disponível em:

http://www.mma.gov.br/port/sdi/ea/deds/pdfs/decltbilisi.pdf. Acesso em: 05 mai. 2017.

ESCALANTE, E. Café y agroforestería en Venezuela. Agroforestería en las Américas, v.4, p.21-24, 1997.

FERRAZ, A. Cultura do Café. Técnico em Agricultura. Instituto Formação. 2013. Disponível em: http://www.ifcursos.com.br/sistema/admin/arquivos/15-0928-apostilacultura docafe.pdf. Acesso em: 02 mai. 2017.

FERNANDES, A; VICENTE DA SILVA, E.; PEREIRA, R. C. M. Fitogeografia do maciço de Baturité: uma visão sistêmica e ecológica. In: BASTOS, F. H. (Org.). Serra de Baturité: uma visão integrada das questões ambientais. Fortaleza: Expressão Gráfica e Editora, 2011.

FERREIRA, B. G. A Estrada de Ferro de Baturité (18701930). Fortaleza: Ed. UFC, 1989.

FREIRE, P. Pedagogia da indignação: cartas pedagógicas e outros escritos. São Paulo: UNESP, 2000.

GADOTTI, M. Educar para a sustentabilidade: uma contribuição à década da educação para o desenvolvimento sustentável. São Paulo: Instituto Paulo Freire, 2008.

GAleti, Paulo A. Pelos Caminhos do Café. Campinas: CATI, 2004.

GIL, A. C. Didática do Ensino Superior. São Paulo: Atlas, 2011.

GIRÃO, R. História Econômica do Ceará. 2.ed. Fortaleza: Casa de José de Alencar - UFC, 2000.

GUTIÉRREZ, F.; PRADO, C. Ecopedagogia e cidadania planetária. 3. ed. São Paulo: Cortez/ Instituto Paulo Freire, 2002. 
JENIZE, E. As Práticas Curriculares e a Extensão Universitária. In: CONGRESSO BRASILEIRO DE EXTENSÃO UNIVERSITÁRIA, 2., 2004. Anais... Disponível em: http://www.ufmg.br/congrext/gestao12.pdf. Acesso em: 2 mai. 2017.

MARTINS, R. M. K. Pedagogia e andragogia na construção da educação de jovens e adultos. Revista Educação Popular, Uberlândia, v. 12, n. 1, p. 143-153. 2013

KOCH, I. V. Desvendando os segredos do texto. 7.ed. São Paulo: Cortez, 2011.

NEVES, C. A estória do café. Rio de Janeiro: Instituto Brasileiro do Café, 1974. 52 p.

REVISTA CAFEICULTURA: História do Café no Brasil, 2011. Disponível em:

http://revistacafeicultura.com.br/?mat $=40384$. Acesso em: 5 mai. 2017.

SAES, A. M. Do vinho ao café: aspectos sobre a política de diferenciação. Informações Econômicos, SP, v.36, fev. 2006. Disponível em:

http://www.iea.sp.gov.br/ftpiea/publicacoes/tec1-0206.pdf. Acesso em: 17 abr. 2017.

SILVA, F. E. DE S. A conservação da biodiversidade da serra de Baturité na perspectiva das unidades de

conservação. Tese (Doutorado) - Universidade Estadual do Ceará, Centro de Ciências e Tecnologia, Programa de PósGraduação em Geografia, Fortaleza, 2015.

SILVA, V. Ensino, pesquisa e extensão: Uma análise das atividades desenvolvidas no GPAM e suas contribuições para a formação acadêmica. Vitória, nov. 2011. Base de dados do Scielo. Disponível em:

$<$ http://www.prac.ufpb.br/copac/extelar/atividades/discussao /artigos/conceitos_de_extensao_universitaria.pdf $>$. Acesso em: 18 mai. 2017

STUDART, G. (Barão de). Ligeiras notas sobre o café no estado do Ceará. Revista do Instituto do Ceará, Fortaleza, t. 42,1928 .

\section{Referência CEJA Donaninha Arruda}

Regimento interno (Versão - 2015);

Projeto Político Pedagógico - 2015;

Plano anual de atividades - 2015.

\section{Notas}

${ }^{1}$ A ecopedagogia é uma proposta que surge dos preceitos da ecologia e tem como base o bom relacionamento homem e natureza.], que, segundo Gadotti (2008), é uma visão mais progressista da educação ambiental.

${ }^{2}$ Sistema Integrado de Gestão Educacional (2016): http://sige.seduc.ce.gov.br/saac/login.asp.

3 O Projeto "LeiturAção" EJA é uma iniciativa dos professores da área de Linguagens e Códigos, com caráter interdisciplinar.

${ }^{4}$ Método que utiliza palavras ou recursos audiovisuais para transmitir uma história, que pode ser contada de improviso ou de forma trabalhada/polida.

${ }^{5}$ É a educação ou ensino para adultos. O termo andragogia vem do grego andros (adulto) e gogos (educar).

${ }^{6}$ Governo do Estado do Ceará. História do café. Disponível em: http://www.ceara.gov.br/historia-do-ceara.

7 A ingazeira é uma árvore nativa das Américas e pode chegar a $10 \mathrm{~m}$ de altura; já o camunzé é nativo da região e tem porte menor. 